\title{
Integrating ambient noise with GIS for a new perspective on volcano imaging and monitoring: the case study of Mt. Etna
}

\author{
Guardo R..$^{\mathrm{a}, *}$, De Siena L. ${ }^{\mathrm{b}, 1}$ \\ ${ }^{a}$ Instituto de Investigaciòn en Paleobiologia y Geologia (CONICET-UNRN), Av. J.A. Roca 1242, (8332) \\ General Roca, Rio Negro, Argentina \\ ${ }^{b}$ University of Aberdeen, School of Geosciences, Dept. Geology and Petroleum Geology, Meston Building, \\ King's College, Aberdeen AB24 $3 U E$ Scotland, UK.
}

\begin{abstract}
The timely estimation of short- and long-term volcanic hazard relies on the availability of detailed 3D geophysical images of volcanic structures. High-resolution seismic models of the absorbing uppermost conduit systems and highly-heterogeneous shallowest volcanic layers, while particularly challenging to obtain, provide important data to locate feasible eruptive centers and forecast flank collapses and lava ascending paths. Here, we model the volcanic structures of Mt. Etna (Sicily, Italy) and its outskirts using the Horizontal to Vertical Spectral Ratio method, generally applied to industrial and engineering settings. The integration of this technique with Web-based Geographic Information System improves precision during the acquisition phase. It also integrates geological and geophysical visualization of 3D surface and subsurface structures in a queryable environment representing their exact threedimensional geographic position, enhancing interpretation. The results show high-resolution 3D images of the shallowest volcanic and feeding systems, which complement (1) deeper seismic tomography imaging and (2) the results of recent remote sensing imaging. The study recovers a vertical structure that divides the pre-existing volcanic complexes of Ellittico and Cuvigghiuni. This could be interpreted as a transitional phase between the two systems. A comparison with recent remote sensing and geological results, however, shows that anomalies are generally related to volcano-tectonic structures active during the last 17 years. We infer that seismic noise measurements from miniaturized instruments, when combined with remote sensing techniques, represent an important resource to monitor volcanoes in unrest,
\end{abstract}


reducing the risk of loss of human lives and instrumentation.

Keywords: Etna, Seismic Imaging, Volcano Imaging, Instrumental developments, GIS-based system, HVSR

\section{Introduction}

Mt. Etna volcano (Sicily, Italy) is the highest volcano of the Eurasian plate (3343m a.s.l.) and one of the most active in the world. Due to its persistent eruptive activity throughout 4 the last century and its proximity to highly urbanized areas, it is highly hazardous and thus

${ }^{*}$ Corresponding author Email addresses: rguardo@unrn.edu.ar (Guardo R.), lucadesiena@abdn.ac.uk (De Siena L.)

${ }^{1}$ http://www.abdn.ac.uk/geosciences/people/profiles/lucadesiena 
It is challenging to obtain high-resolution seismic images of a volcanic edifice. Seismic methods based on coherent-wave propagation are affected by site effects, highly-reflective topography, and complex 3D propagation effects. These corrupt both seismic phases and amplitudes, which are better described by stochastic models and resonance [Neuberg and Pointer, 2000; Wegler, 2003; De Siena et al., 2014, 2016]. A full 3D imaging of these Earth layers is hindered by the lack of a dense seismic network, with node spacing of the order of e. g. $250 \mathrm{~m}$ [Kiser et al., 2016]; this lack is due to the elevated economic costs, installation difficulty, high level of risk for operators when installing standard seismic stations, and has been used as a valid argument for the development of alternative geophysical imaging techniques in volcanoes [Carbone et al., 2014].

In this study, we try to close the gap between deep travel-time tomography imaging, surface geomorphology information, and shallow feeding systems modelling, using the Horizontal to Vertical Spectral Ratio (HVSR) method integrated with the Geographic Information System (GIS). The HVSR technique uses seismic ambient noise data recorded at a single station and has been developed in the framework of civil engineering to study resonance frequencies of buildings [Nakamura, 1989; Parolai et al., 2002]. The method has already been used in Earth subsurface imaging, with applications spanning from the characterization of thermal basins [Galgaro et al., 2014] to the study of lateral heterogeneity in small alluvial valleys [Chávez-García and Kang, 2014]. Surface waves (the main constituents of ambient noise) can reveal novel information about the structure of the volcanic edifice [Neuberg and Pointer, 2000]. The method may thus represent the right complement to passive tomographic imaging, providing shallow geological information. Still, in volcanoes, the HVSR is generally used to measure seismic site effects only [Mora et al., 2001]. Almendros et al. [2004] improve the HVSR method and apply it at Teide volcano. The authors estimate a time-dependent HVSR and create vibration frequencies maps across the summit area of the volcano. Merging their HVSR results with different methodologies and geological constraints they achieve an adequate interpretation of the shallow subsurface volcanic structures.

Remote sensing is an important alternative to seismic imaging when investigating the shallowest volcanic crust. Using DInSAR and GPS data to study ground deformation, it 
was possible to locate in space and time the position of the dike that produced the 2008 eruption of Mt. Etna [Currenti et al., 2011]. Using GIS in combination with the HVSR method opens a path (1) to see beyond the shape and dimensions of the structures, for an improved correlation with geomorphological information; (2) to locate anomalies in space exactly and perform query to measure relevant quantities like volume, size, and extension of the anomalies [Barreca et al., 2013]; (3) to precisely overlap any kind of map (thermal, tectonic, geological, tomographic, etc.), constraining the interpretation of the seismological results [De Siena et al., 2016]. Mount Etna is one of the most studied volcanoes in the world, thus the perfect laboratory to test new methods to image the uppermost part of volcanic cones, with the aim of better predicting future shallow magma ascending path. The experiment of joint seismic and GIS data acquisition as well as the feasible automation of data collection and analysis via the development of smaller instrumentation [Middlemiss et al., 2016] will then represent a feasible resource for hazard assessment solution during volcanic crises.

\section{Geological and structural background}

Mount Etna volcano is considered a relatively young volcano with a developing process started about $500 \mathrm{ka}$ ago, in the Quaternary. The volcano is divided into 4 supersynthems and 8 synthems, according to the isotopic datation of De Beni et al. [2011]. The actual shape of the volcano is the result of the last synthem ("Il Piano synthem"), begun around $10.4 \mathrm{ka}$ ago. It has an extension of $47 \mathrm{~km}$ from North to South and $38 \mathrm{~km}$ from East to West and an area of about $1200 \mathrm{~km}^{2}$.

The volcano is located at the boundary between the Calabro-Peloritan Arc (North) and the Hyblean foreland (South) [Branca et al., 2004; Lentini, 1982; Gillot et al., 1994]. On the eastern shore of Etna (and Sicily) there is the "Malta-Hyblean escarpment", an important system of faults that extends uninterrupted from Malta to the Aeolian Islands passing through the Hyblean area (Fig. 1).

The Maltese-Hyblean-Aeolian faults system is considered the main discontinuity between the African plate (West) and the Ionian oceanic microplate (East) [Gvirtzman and 


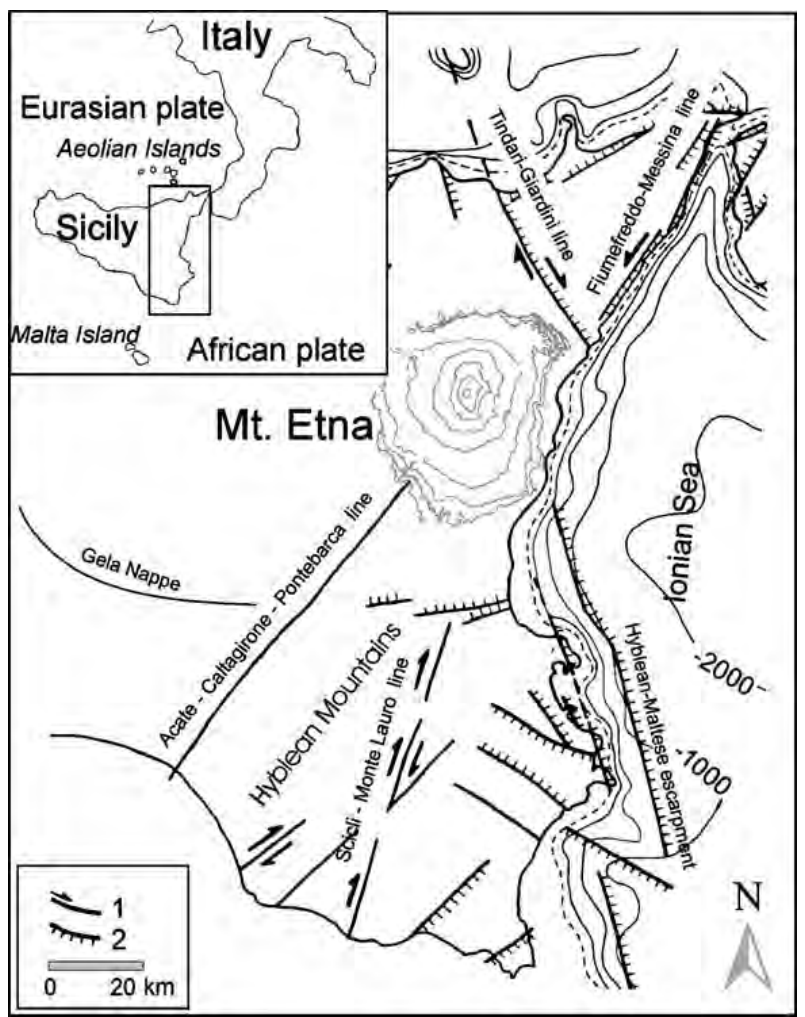

Figure 1: Geological-structural sketch of eastern Sicily from Patanè et al. [2006b]. The legend in the lower left panels marks with (1) the main tectonic lines and (2) the main faults. The Etnean area and its topography are highlighted using contour lines.

Nur, 1999] as well as the major contributor to the volcano feeding system through an asthenospheric window [Lanzafame and Bousquet, 1997]. The western sector, named by Patanè et al. [2006b] "Domain a" (Fig. 2), is characterized by faults and fractures with a prevalent NE-SW direction. The intersection of "Domain a", comprising NE-SW-oriented structures, and "Domain b" (Fig. 2), comprising NW-SE-oriented structures, creates discontinuities that are considered the main cause of magma uprising to the main craters [Patanè et al., 2006b].

\section{Instruments and Data}

In this study, we combine geophysical techniques with information and communication technologies (ICT) and remote sensing. Seismic data were recorded by a single seismic 


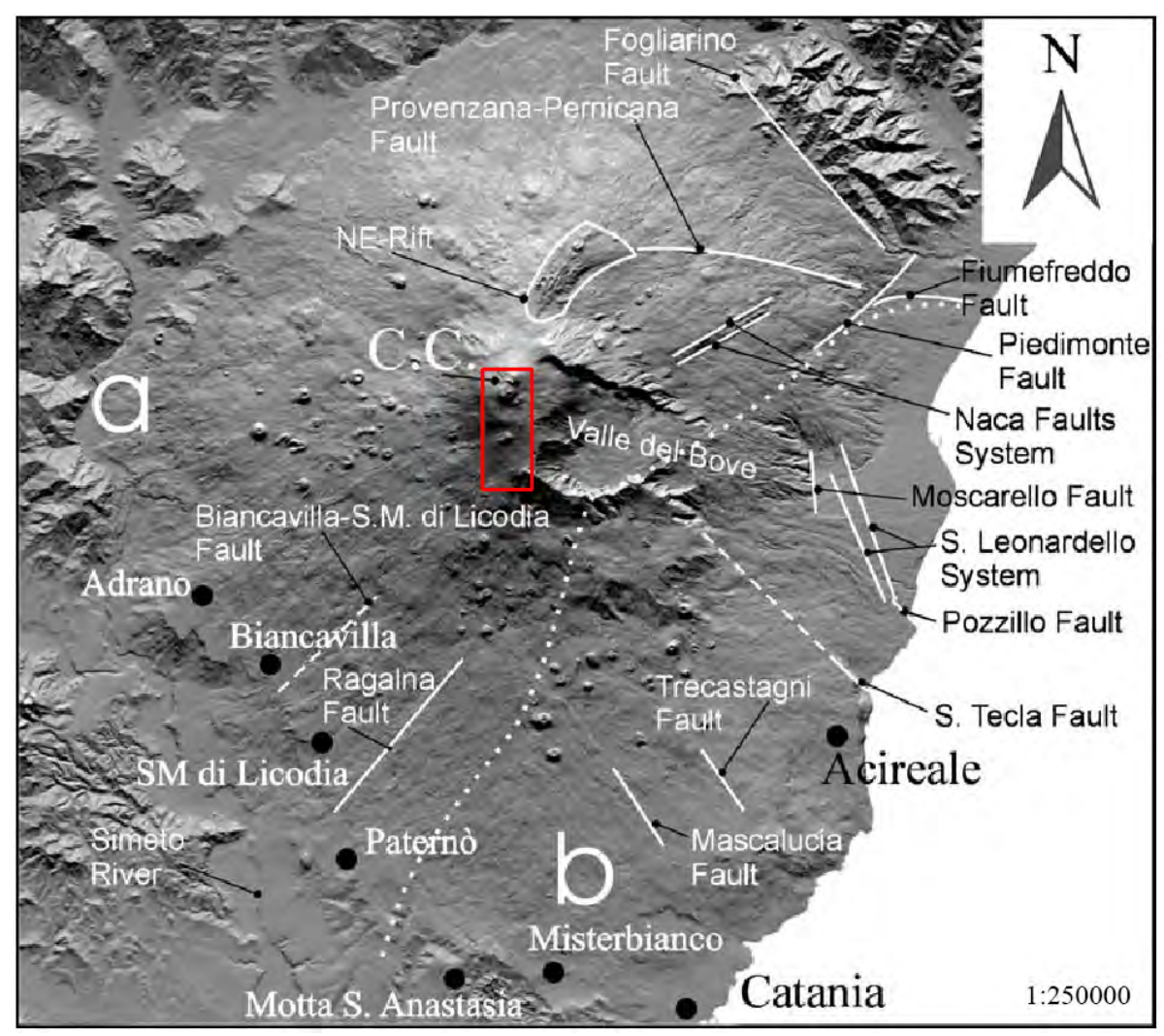

Figure 2: Structural framework of Mount Etna from Patanè et al. [2006b]. Domain "a" is characterized by structures with a prevalent NE-SW orientation. In the domain "b" the NW-SE and NNW-SSE structures are predominant. The two areas are separated by a white dotted line. The red rectangle outlines our study area.

station, which was moved in space in order to apply the HVSR technique. As ICT and remote sensing, we used a GIS environment, a tablet PC, and a GPS antenna. The first phase of the study has been the creation of the workspace inside the GIS environment. In the second phase, we acquired field data. Finally, data have been elaborated in a joint geophysics and GIS environment.

\subsection{GIS and WEBGIS}

The setup of a workspace implementing a reliable coordinate system and including all available data from literature is a fundamental step to develop an accurate field work [Barreca et al., 2013]. We chose an area of $10.5 \mathrm{~km}^{2}$ located between 14.98 and 15.00 longitude $\mathrm{E}$ and 


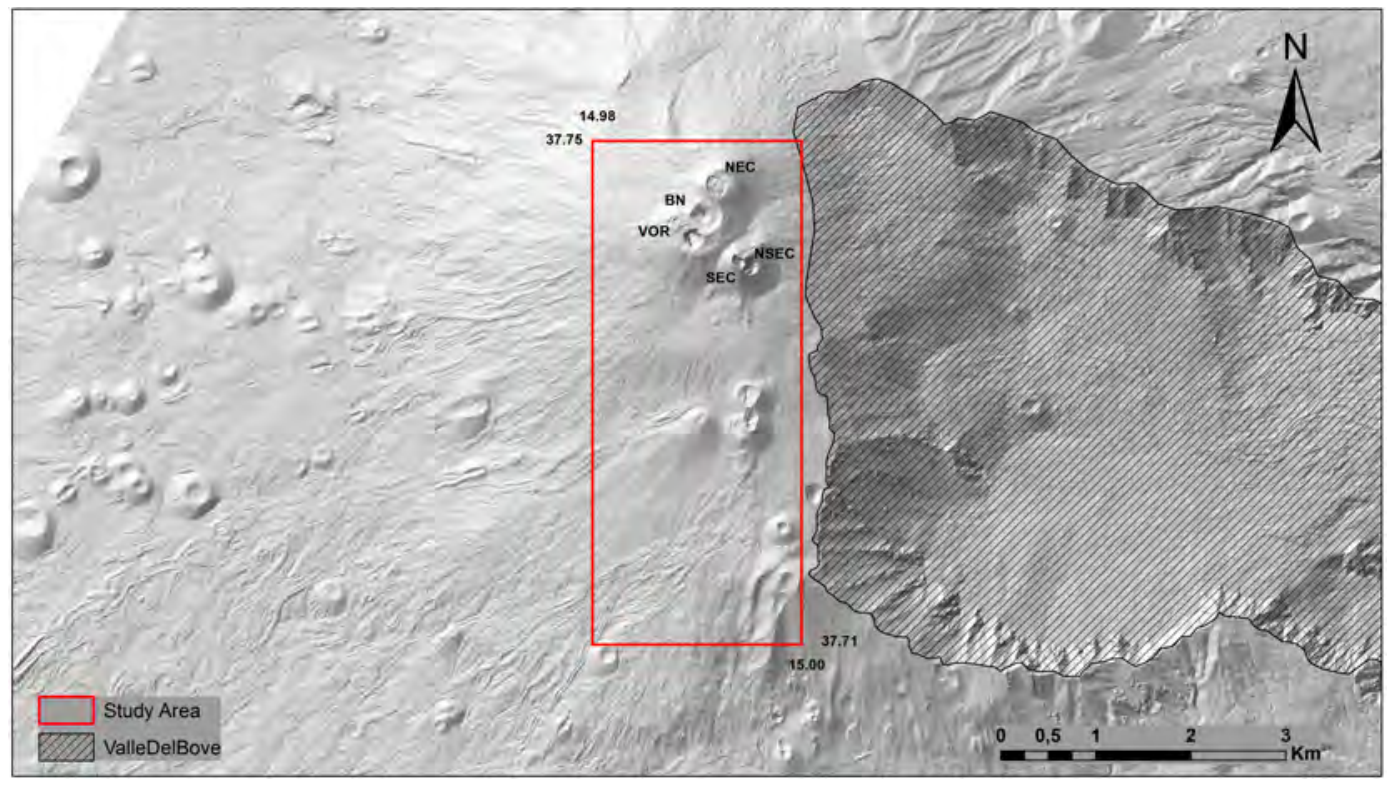

Figure 3: Digital Elevation Model of Mt. Etna as basemap. The main craters are indicated (VOR, Voragine; BN, Bocca Nuova; NEC, NE Crater; SEC, SE Crater; NSEC, New SE Crater).

37.71 and 37.75 latitude $\mathrm{N}$, spanning altitudes between $2281 \mathrm{~m}$ and $3265 \mathrm{~m}$ a.s.l. (Fig. 3).

The area was subsequently subdivided into $22 \mathrm{~W}$-E oriented lines and 9 S-N oriented lines, with nodes spaced $250 \mathrm{~m}$, giving an array of 21 rows and 8 columns. The intersections of these lines form 198 points. 37 of these points were cut off, due either to their proximity to the craters or to the time restrictions during acquisition, thus performed at a total of 161 points (Fig. 4).

To allow us to be more accurate on reaching the measurement points we created, for each point, 3 buffer circles at 5, 10 and 15 meters, respectively. Two basemaps were added to the workspace as final step of the set up: a digital elevation model (DEM) of Mount Etna and a topographic map with a scale 1:10000 [Bisson et al., 2016]. The workspace was then uploaded to a server in order to obtain a WebGIS, which is a combination of the WEB standards with geographic information system [Fu and Sun, 2010]. Hence, we were able to use this online map operating on a portable device (tablet PC) and carry it to every measurement point. Due to the risk of losing connectivity, the map was also downloaded into the tablet local storage. 


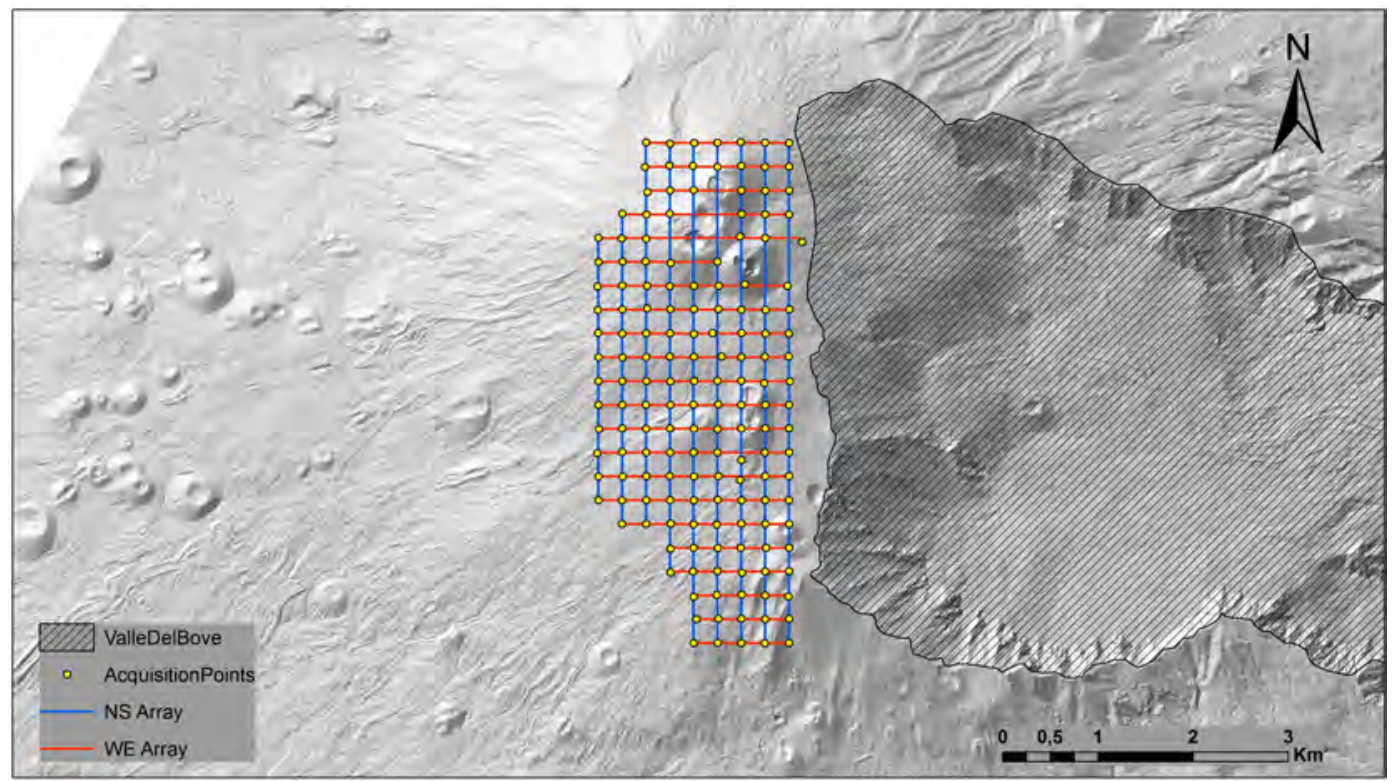

Figure 4: Digital Elevation Model of Mt. Etna as basemap. The $22 \mathrm{~W}-\mathrm{E}$ arrays (red) and 9 S-N arrays (blue) are imposed on the topography.

\subsection{Seismic data collection experiment}

To reach the 161 points created during the setup phase we used a tablet PC with a CPU Quad-core 1.4 GHz Cortex-A9, 2GB of RAM, and an internal GPS. This was supported by an external GPS antenna equipped with a chipset SiRF Star III, a 20 channels receiver, able to process signals from all the visible satellites GPS and WAAS, a frequency of $1575,42 \mathrm{MHz}$ and a TTFF (Time to First Fix) lower than 1 second. We were able to see in real time our position in the field thanks to the connection to the WebGIS and/or the map available on the tablet PC. With respect to the set of measurement points, we obtained a precision of:

- $66 \%$ in positioning inside the buffer radius of 5 meters;

- $84 \%$ in positioning inside the buffer radius of 10 meters;

- $91 \%$ in positioning inside the buffer radius of 15 meters.

This means that just $9 \%$ of the measurements were located outside the buffer radius of 15 meters (Fig. 5). 

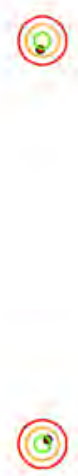

\section{$1: 2500$}

(6)
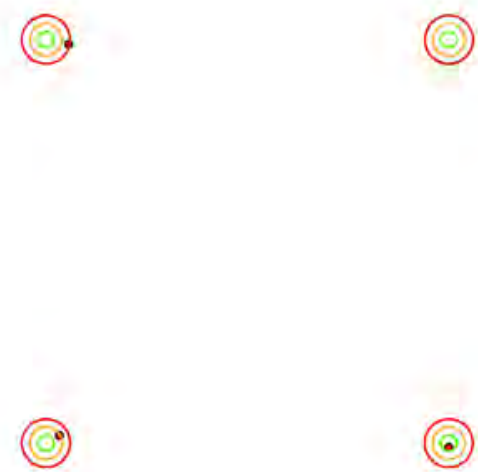

Figure 5: The example area shows the buffer radius of 5 meters (in green), 10 meters (in orange) and 15 meters (in red). The red dots indicate the acquisition points.

The seismic instrument, a compact seismometer (24 bit digital) equipped with 3 accelerometric channels and 3 velocimetric channels with adaptable dynamic range, was suitable for seismic ambient noise recordings (up to $1.5 \mathrm{~mm} / \mathrm{s}$ ) due to its high sensitivity and a frequency operating range between 0.1 and $1024 \mathrm{~Hz}$ on all channels. It was located at each of the 161 measurement points. The positioning on the ground was done considering several factors:

- Coupling with the soil, we used the ash of the volcano to smooth the impedance contrast;

- Setting horizontally with the spirit level;

- Orienting to the North.

The acquisition duration at each of the 161 points was 20 minutes with a $128 \mathrm{~Hz}$ sampling rate, meaning that signals are investigated up to a frequency of $64 \mathrm{~Hz}$, i.e., half of the sampling rate of the discrete signal processing system. The period of acquisition is May 11- June 11 2014. The volcanic tremor in this period can be considered stationary, with a 
variation of $13.7 \%$ in amplitude and $2.6 \%$ in frequency (G. Di Grazia, INGV-Osservatorio Etneo, personal communication).

\section{Methods and Data Processing}

The Horizontal to Vertical Spectral Ratio (HVSR) technique, applied first by Nogoshi and Igarashi [1970, 1971] and also known as "Nakamura's method" [Nakamura, 1989], states that the ratio between the horizontal and vertical spectral amplitudes of the natural microtremors (volcanic noise in this case) eliminates the seismometer transfer-function and gives the amplification produced by a surface layer at the recorded site. Even if, as of today, there are several studies that have applied the method to different scopes, one of the main hypothesis regarding the subsurface (geology) is that the fundamental frequency is linked to the depth and seismic velocity of a layer topping a relevant acoustic impedance contrast [Lachetl and Bard, 1994]. The fundamental resonance frequency $F_{0}$ for a continuous stratified layer is given by the equation:

$$
F_{0}=V_{s} / 4 H
$$

where $V_{s}$ is the shear wave velocity and " $4 \mathrm{H}$ " is 4 times the depth of the contrast. Lermo and Chávez-García [1994] and Dravinski et al. [1996] state that the method is valid in the assumption that microtremors are composed by surface (Rayleigh) waves, which propagate inside a surface layer over an infinite half-space. Nevertheless, data-driven studies generally agree that the HVSR mainly reveal the fundamental (resonant) frequency of the shallow structure beneath the investigation site [Field and Jacob, 1995; Lachet et al., 1996; Seekins et al., 1996; Coutel and Mora, 1998].

The extension of the method to a stratified multi-layered system was given by Konno and Ohmachi [1998]. Since then, the method has been considered reliable when the structures beneath the investigation site can be approximated by a 1-D model. Nevertheless, a recent study of lateral heterogeneity in small alluvial valleys made by Chávez-García and Kang [2014] proves that the method reasonably shows the natural vibration frequency of complex $2 \mathrm{D}$ structures, at least when there is a high impedance contrast between a sedimentary layer 


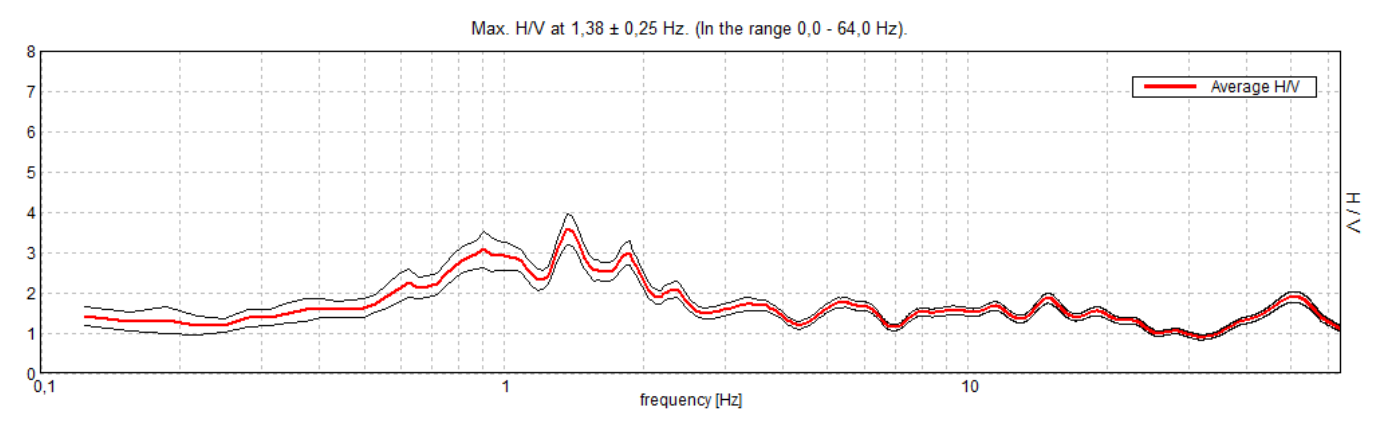

Figure 6: Sample of $\mathrm{H} / \mathrm{V}$ ratios as a function of frequency. The red and black solid lines indicate the $\mathrm{H} / \mathrm{V}$ mean value and standard deviation, respectively.

and a bedrock. The method has already been applied to a volcanic environment (Arenal volcano, Costa Rica) by Mora et al. [2001]. These authors show that reliable HVSRs can be obtained from different types of volcanic media, with lateral heterogeneity in the shallow structures producing large variations along the array. The main result is that local amplifications observed in the spectral bands, corresponding to different peaks in the spectral ratios, are related to shallow geological structures. In their interpretation, the lack of pronounced discontinuity between a shallow soft depositional layer and a deep competent materials is marked by very low amplitudes. Galgaro et al. [2014] demonstrate that the HVSR peak broadness can be related to thermal properties. In addition, low seismic frequencies (3 $\mathrm{Hz}$ ) highlight shallow structures in a volcanic environment such as deposited debris flows [De Siena et al., 2016], at least when using alternative stochastic (coda) waves. With the HVSR, just a few minutes of acquisition of seismo-volcanic noise are sufficient to stabilize results. Information achievable from the resonant frequencies is then precisely linked to location with the implementation of the GIS approach, thus increasing spatial correlation between the measurements and local geology.

In the acquisition of the relative $\mathrm{H} / \mathrm{V}$ spectral ratios (Fig. 6) from volcanic noise amplitudes we took into account the position of the 161 data points as well as the difficulties and restrictions of Nakamura's method. We use the standard inversion method that assumes a velocity-depth function, to compute the resonant frequency $F_{0}$ [Ibs-von Seht and Wohlenberg, 1999; Amorosi et al., 2008]. This function is calculated using an average shear-wave 
velocity of $1250 \mathrm{~m} / \mathrm{s}$ at the base of the volcanic edifice, derived from Alparone et al. [2012] and assuming a velocity of $450 \mathrm{~m} / \mathrm{s}$ in the shallowest layers. This last value is obtained by the seismic refraction experiment of Cassinis et al. [1969]. Differently from geotechnical applications (e.g Amorosi et al. [2008]) our objective is to compare H/V functions with volcanological maps, not to obtain the exact stratigraphy at each point. Hence, we perform a high-resolution spatial analysis based on point interpolation with an approach similar to the one devised and tested by Almendros et al. [2004]. At each measurement point laying on the lines created during the set up of the GIS workspace we obtain the related "ratiograms". These HVSR functions are shown as a 2-dimensional contour plot versus frequency and time (See Supplementary Fig. 1) and were created to check for the presence of transient signals, which invalidate the assumption of noise stationarity. After removal of these transients we interpolate the ratiograms on the same line in space. The resulting HVSRs functions are displayed in a 2-dimensional contour plot versus depth (displayed in meters above sea level) and distance (in meters - Fig. S2).

We obtain 31 vertical cross-sections, 9 S-N oriented with a length span between $2750 \mathrm{~m}$ and 5250m (Fig. S3 and S4), and 22 with a W-E orientation (Figs. S5, S6, S7, S8 and S9), with a minimum length of $975 \mathrm{~m}$ and a maximum length of $2135 \mathrm{~m}$. The depth spans between $1400 \mathrm{~m}$ and $3200 \mathrm{~m}$ a.s.l. while resolution is approximately $200 \mathrm{~m}$. The $\mathrm{H} / \mathrm{V}$ ratios are highlighted using contour lines in a range between 1 an 4.5.

Doing a spline interpolation between the points obtained from the intersection of a horizontal plane and the $\mathrm{H} / \mathrm{V}$ ratio contour lines of the vertical cross-section, we additionally obtain 9 horizontal cross-sections in a depth span between $1600 \mathrm{~m}$ and $3200 \mathrm{~m}$ a.s.l. (excluding $1400 \mathrm{~m}$ a.s.l. where we had a limited number of intersection points). The gap between layers is $200 \mathrm{~m}$. From the contour lines of the horizontal cross-section we extrapolated several polygons for the different value of the $\mathrm{H} / \mathrm{V}$ ratio. To correlate the distribution of these horizontal cross-sections with the volcano-tectonic setting we took into consideration: (1) the main alignment of the polygons and (2) the main angle direction outlined by the segments constituting the polygons. From the HVSR contour line map we select polygons defined by the first closed loop to avoid any misinterpretation due the spatial interpolation; 


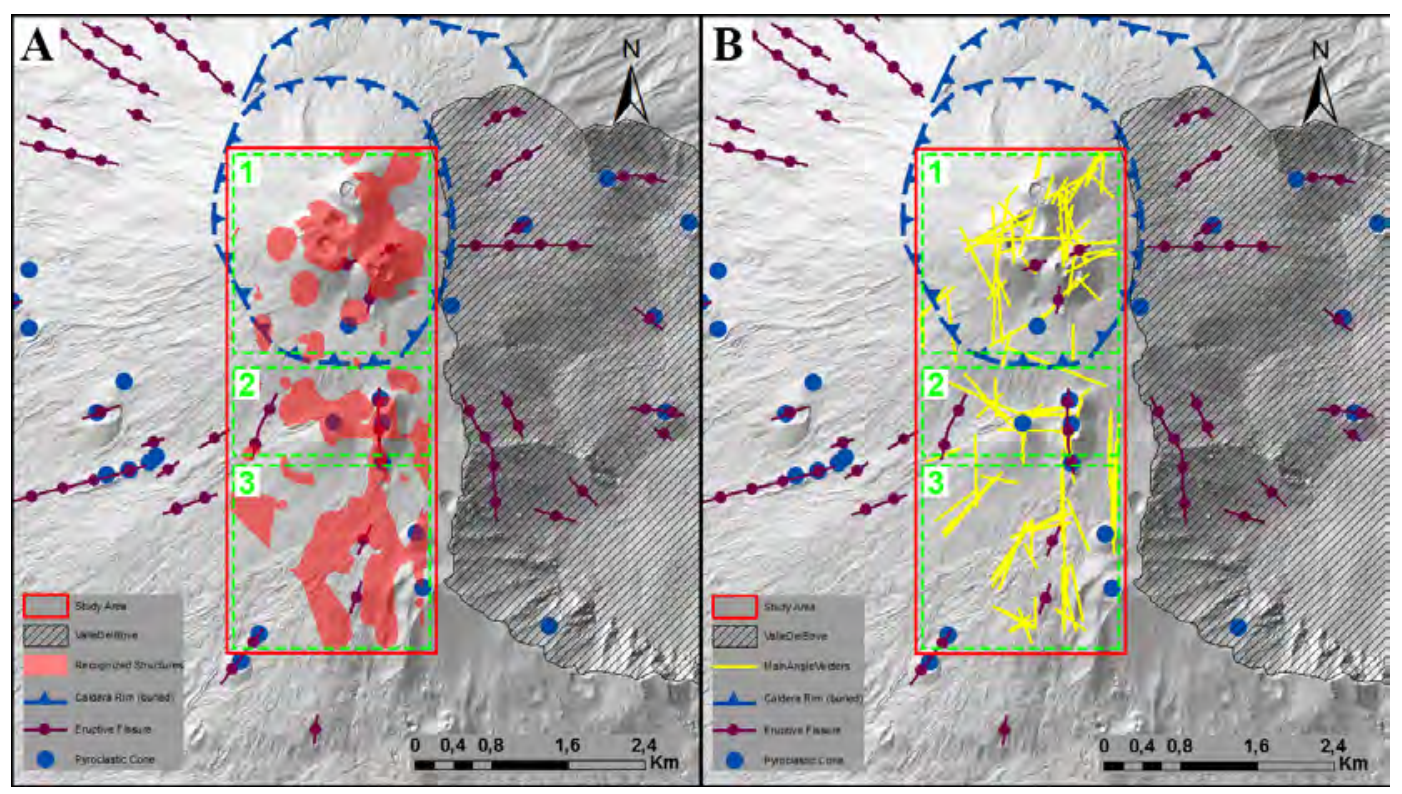

Figure 7: A: Map view of the polygons with $\mathrm{H} / \mathrm{V}$ ratio equal and higher than 3.5. B: Distribution of the vectors lines obtained from the polygons' main angle. The eruptive fissures, pyroclastic cones and caldera rim are obtained from the "Volcano-Tectonic Map of Etna Volcano" [Azzaro et al., 2012]. The green boxes indicate the three main clusters discussed in the text.

this value describes polygons corresponding a value equal and higher than 3.5 (Fig. 7A). The main angle direction of the polygons was calculated using the GIS tool "CalculatePolygonMainAngle". This calculates the dominant angles, i.e., the orientations of segments forming the input polygon features that are measured most frequently. We then plot the segments as yellow oriented vectors on the volcano-tectonic map of Etna made by Azzaro et al. [2012], including the eruptive fissures, the pyroclastic cones, and the caldera rim (Fig. 7B). Keeping into consideration the sum of the length of the vectors with the same orientation we observe: (1) absolute vector maxima along the N-S direction; (2) two relative maxima along the NE-SW and E-W directions. The NW-SE trend is the least represented.

After importing the polygons delineated by the contour line with $\mathrm{H} / \mathrm{V}$ ratio equal and higher than 3.5 in the 3D GIS environment, we gave them a vertical extrusion of $200 \mathrm{~m}$, filling the gap between layers. Fig. 8 shows a 3D image of the real geographic position of the recognized structures from a pitch angle of $30^{\circ}$ (Fig. 8). 


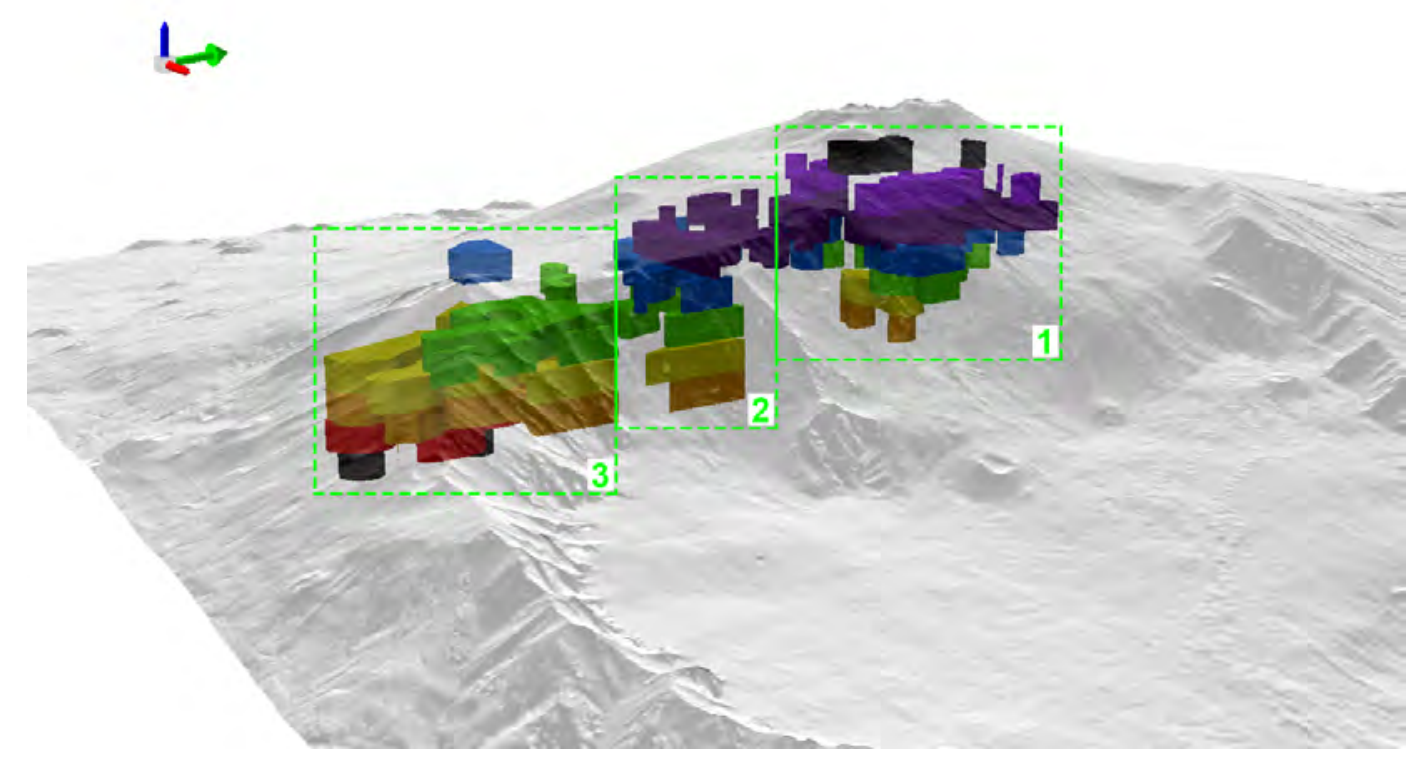

Figure 8: 3D view from a pitch angle of $30^{\circ}$ of the recognized clusters. The green arrow on the upper left corner shows the North. The extruded polygons have a thickness of $200 \mathrm{~m}$. The colour legend is (from bottom to top): black, red, orange, yellow, green, blue, indigo, violet and black and indicate depths from $1600 \mathrm{~m}$ to $3200 \mathrm{~m}$. a.s.l.. The green boxes indicate the three main clusters discussed in the text.

\section{Results and Discussions}

The results reveal three main anomalies: two are located South of the caldera rim (Fig. 7A2-3) while the third is inside it (Fig. 7A1). Vectors orientations South of the old caldera rim of the Ellittico volcano follow the N-S and NE-SW trends (Fig. 7B2-3), differing from those inside the caldera (Fig. 7B1). These trends are related to fractures with the same orientation, considered as preferential way for the magma uprise [Acocella and Neri, 2003]. The same orientations are drawn on the INGV tectonic map of Azzaro et al. [2012] by pyroclastic cones and eruptive fissures. A similar spatial correlation is visible between all the fissures post 1900 described by Neri et al. [2011] and both the polygon map (Fig. 9A) and the vectors map (Fig. 9B).

Inside the rim, vectors mainly highlight the W-E and NW-SE trends, showing clear correlation with eruptive fissures directions on the north-western and eastern sides of the volcano (Valle Del Bove - Fig. 10). 


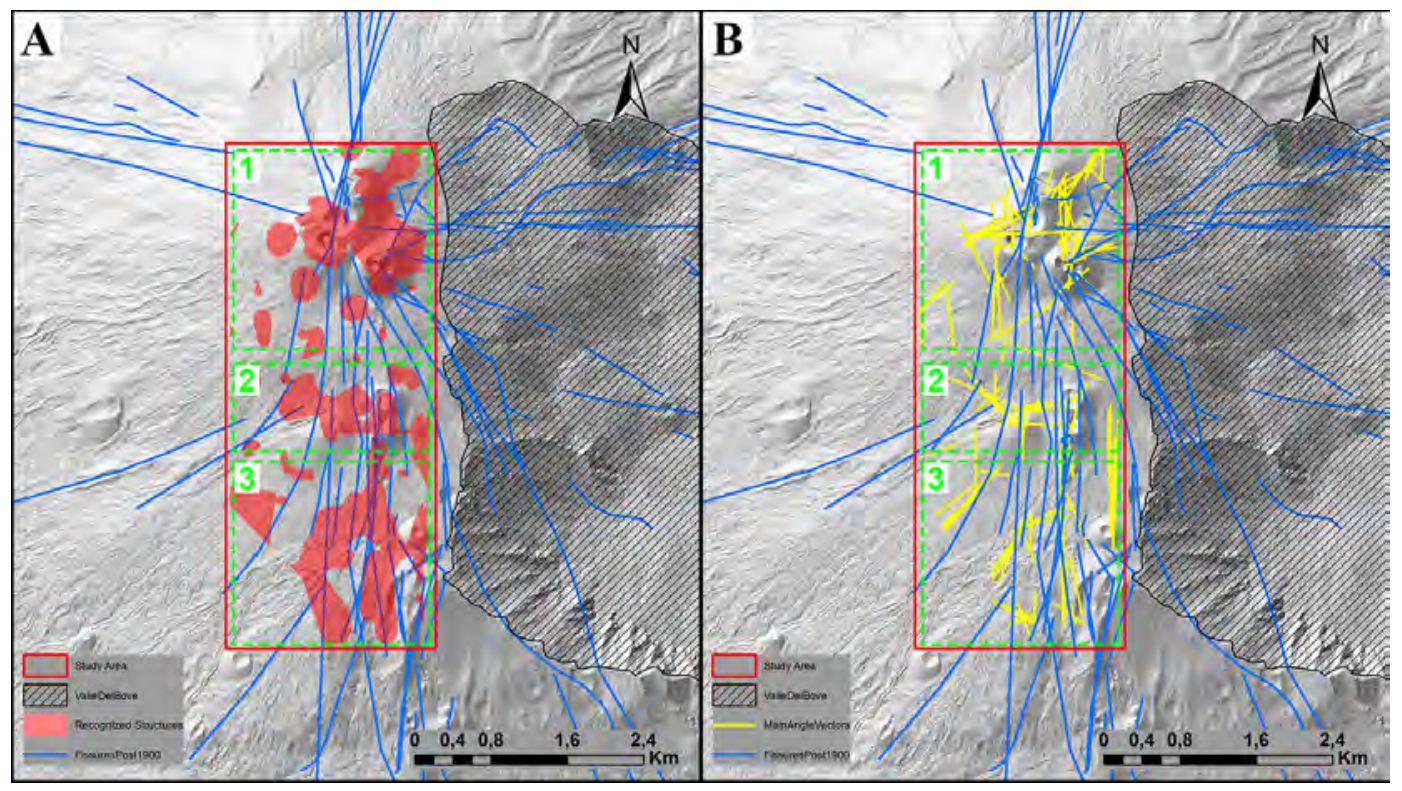

Figure 9: Correlation between the eruptive fissure post 1900 and (A) the polygon map and (B) the vectors lines obtained from the polygons' main angle.The green boxes indicate the three main clusters discussed in the text.

The southernmost and northernmost high-H/V structures could be associated with preexisting volcanic centres. They are in reasonable spatial correlation with a cooled pathway of magma (i.e. a system of dikes) at Cuvigghiuni [Branca et al., 2004] (box number 3 in Figs. 7,8 and 9) and in the Stratovolcano Supersynthem (i.e. the centers of the Ellittico and Mongibello [Branca et al., 2011a]) inside the Ellittico caldera (box number 1 in Figs. 7,8 and 9). Referring to the cross-section of the Geological Map of Etna [Branca et al., 2011b], the recognized structures intersect the Zappini, Concazze and Il Piano Synthems. The central anomaly (box number 2 in Figs. 7,8 and 9), however, does not correspond to any known pre-existing structures. Considering that the Cuvigghiuni center (South) is dated between $79.6 \pm 4.2 \mathrm{ka}$ and $65.3 \pm 4.4 \mathrm{ka}$ ago and the Stratovolcano centers (North) are dated between 56.6 $\pm 15.4 \mathrm{ka}$ and $15 \mathrm{ka}$ ago [De Beni et al., 2011] the central connecting structure could be an intermediate volcanic center not dated yet, and with no evidence on topography (Fig. 8-2). The high-H/V structures, however, are also in strong spatial correlation with the results of recent studies carried out using remote sensing analysis (Fig. 


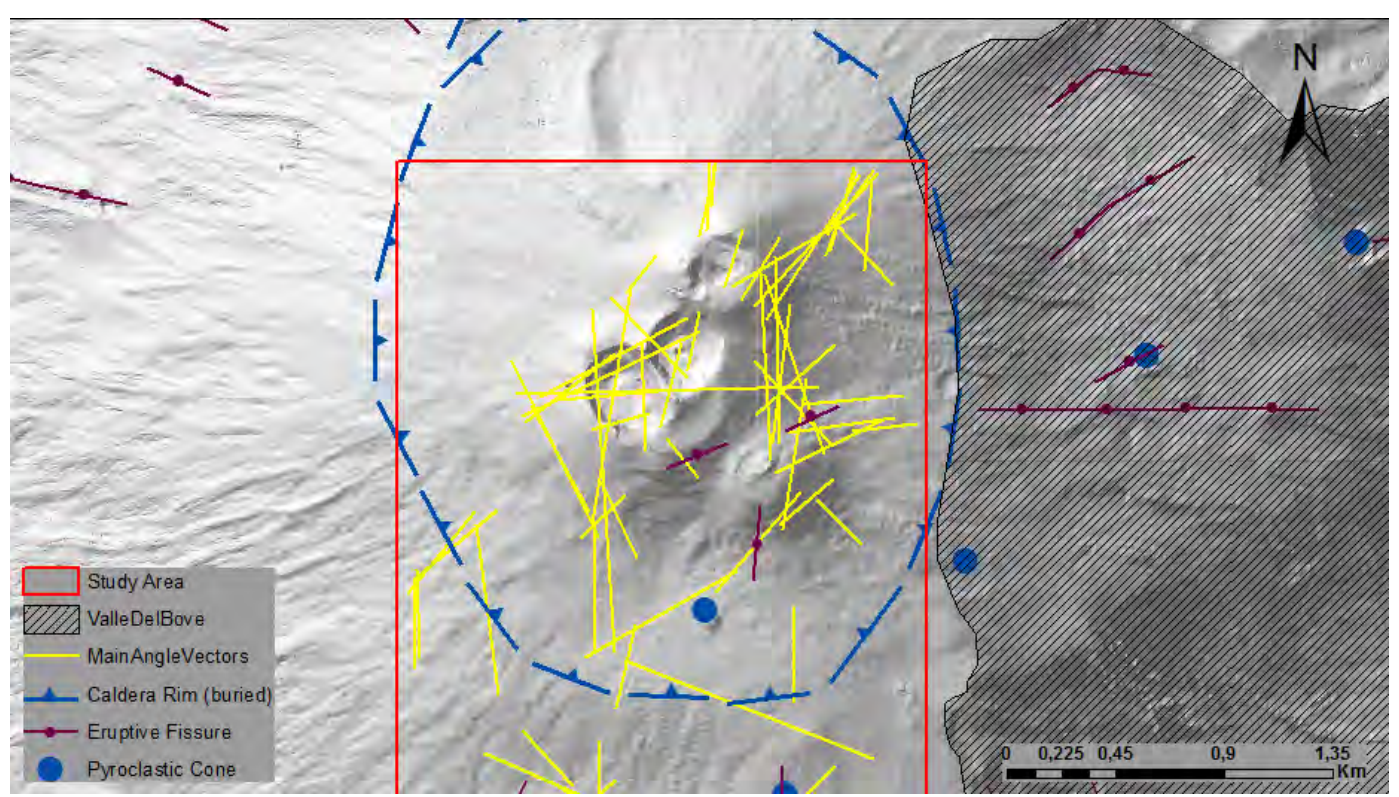

Figure 10: Detail of the vectors orientation inside the Ellittico caldera rim.

11) and discussed in the following sections.

\subsection{Monte Frumento Supino and Montagnola Clusters}

The structures comprised in the southern and intermediate clusters are located between $1600 \mathrm{~m}$ a.s.l. and $2800 \mathrm{~m}$ a.s.l.. The anomalies retrieved between depths of $1600 \mathrm{~m}$ and 1800 $m$ a.s.l. have the same orientation of the eruptive fissures and follow the eruptive vents in the southern part of the study area (see detail in Fig. 12). Using seismic and geodetic data, Acocella and Neri [2003] highlight the dike that produced both the 2001 eruption at Piano del Lago and the deformation beneath Montagnola, producing uplift along a N-S trend. Resonant anomalies between $2000 \mathrm{~m}$ and $2400 \mathrm{~m}$ a.s.l. (thus comprising the depth range of the dike) show a similar N-S trend, (D1, Fig. 13), generally bordering the inferred location of the dike. Due to their spatial relation with eruptive fissures, we infer that the solidified dike acts as a quasi-vertical barrier for seismic noise, constraining the anomaly under areas of higher fracturing and temperature.

The correspondence between the recognized structures and the elements of the volcanotectonic map is even more evident for the intermediate cluster (Fig. 13). The resonant structures between $2600 \mathrm{~m}$ and $2800 \mathrm{~m}$ a.s.l. are mainly located beneath both Monte 


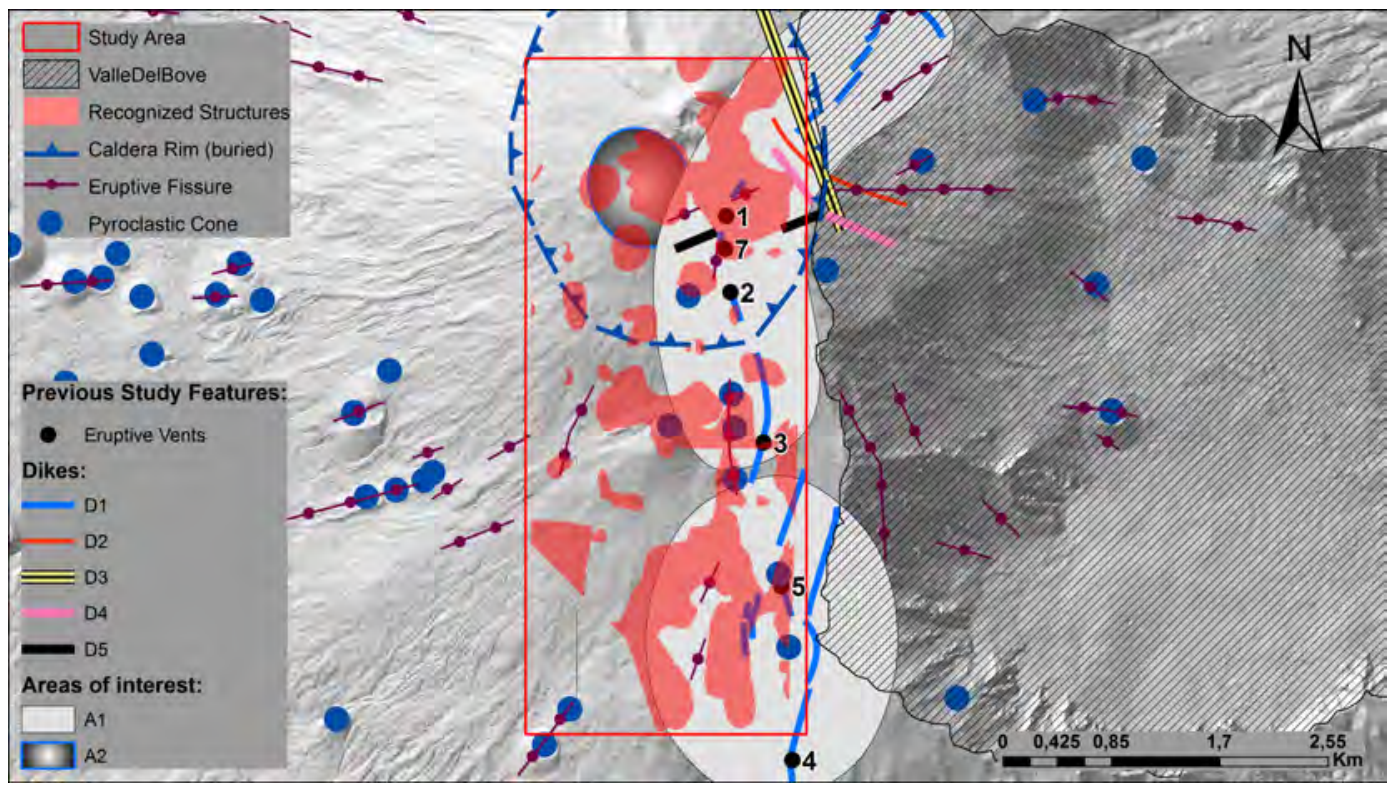

Figure 11: Comparison between the recognized structures and previous studies.In detail, the eruptive vents were described by Acocella and Neri [2003]; Behncke and Neri [2003]. dikes: D1 - [Acocella and Neri, 2003], D2 and D3 - [Aloisi et al., 2009], D4 - [Bonforte et al., 2013], D5 - [Bonforte and Guglielmino, 2015]. A1 marks the deformation area highlighted by [Acocella and Neri, 2003] while A2 is the Hypocenter location described by [Saccorotti et al., 2007].

Frumento Supino and the eruptive vents opened at about $2790 \mathrm{~m}$ elevation during the 17 July-8 August 2001 eruption [Behncke and Neri, 2003]. The anomalies could also shape the dike's intrusion that generated the October 262002 eruption in the same area [Aloisi et al., 2003].

\subsection{Crater Cluster}

The resonant structures in the northern cluster, inside the crater, confirm the existence of a system of dikes in the area close to the SE craters (SEC) and the New SE Crater (NSEC), where our model shows resonant structures between $2400 \mathrm{~m}$ and $3200 \mathrm{~m}$ a.s.l.. This system formed the eruptive fissures and the vents 1, 2 and 7 described by Acocella and Neri [2003] during the 2001 eruption, which coincide with the F1, F2 and F3 vents described by Behncke and Neri [2003] (Fig. 14). The above-mentioned structures also depict the intrusion that caused the eruptive fissures delineated by Bonaccorso et al. [2011] and Bonforte et al. [2013] 


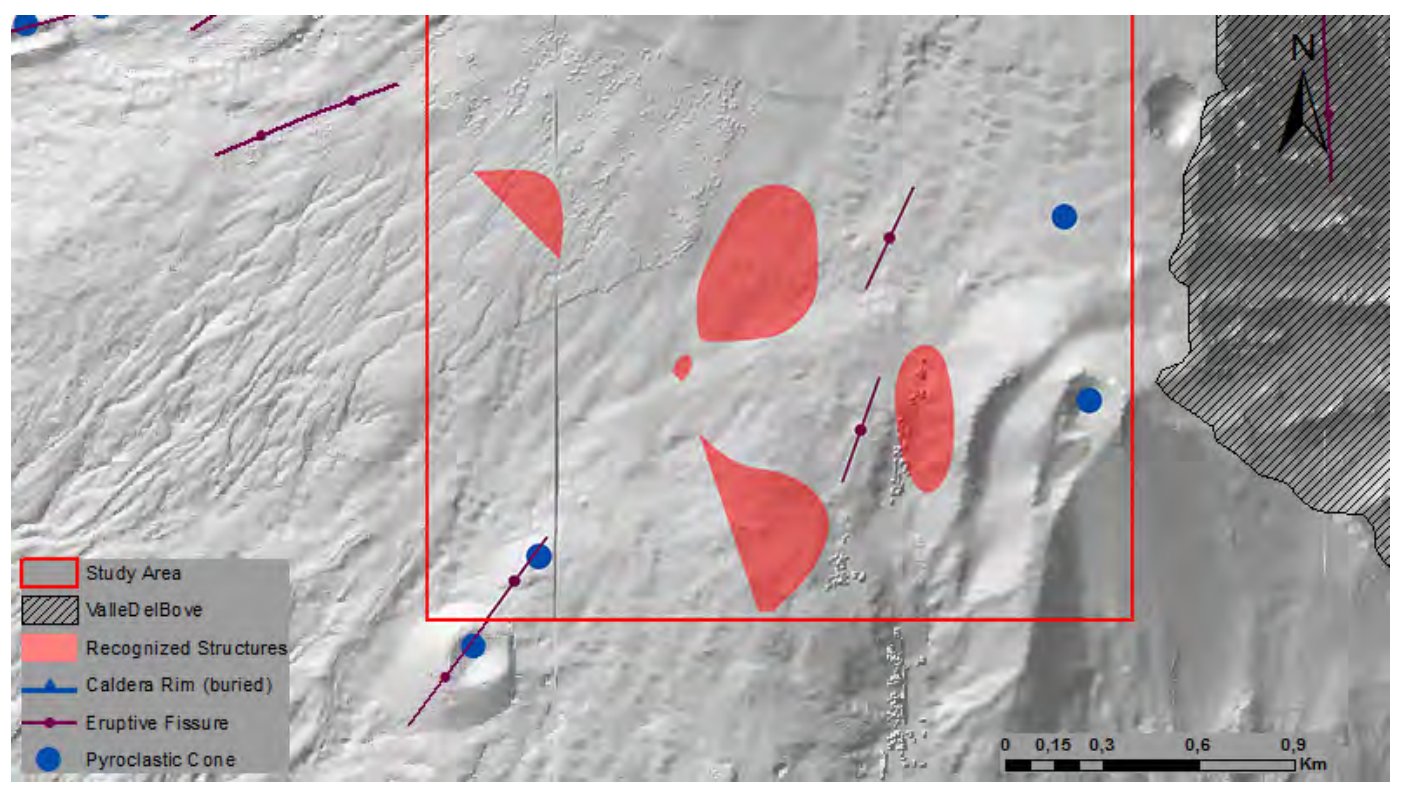

Figure 12: Comparison between the recognized structures at depth of $1600 \mathrm{~m}$ and $1800 \mathrm{~m}$ a.s.l. and the elements of the volcano-tectonic map in the southern part of the study area.

during the 2008-2009 eruption and Bonforte and Guglielmino [2015] during the 2014 eruption (Fig. 14). Considering their orientation, from $2600 \mathrm{~m}$ a.s.l. to the surface, the model confirm (1) the hypothesis of the influence of flank spreading on the summit crater area, considering the angles N-S oriented between SE and NE craters, and (2) the role of the upper NE Rift in radial magma intrusion (from NEC), considering the NE-SW angle orientation at North of the NEC (Fig. 10 and 14) [Bonforte et al., 2007]. Finally, in the area of Voragine (VOR) and Bocca Nuova (BN), both parts of the central crater, the model reconstructs the body that causes the seismicity analyzed by Saccorotti et al. [2007] (Fig. 14).

We conclude that our results reconstruct the shallowest feeding systems of Etna. In the supplementary materials we provide a dynamic 3D visualization of the model to help in the understanding of the spatial correlation of the model with the above-discussed volcanotectonic structures. 


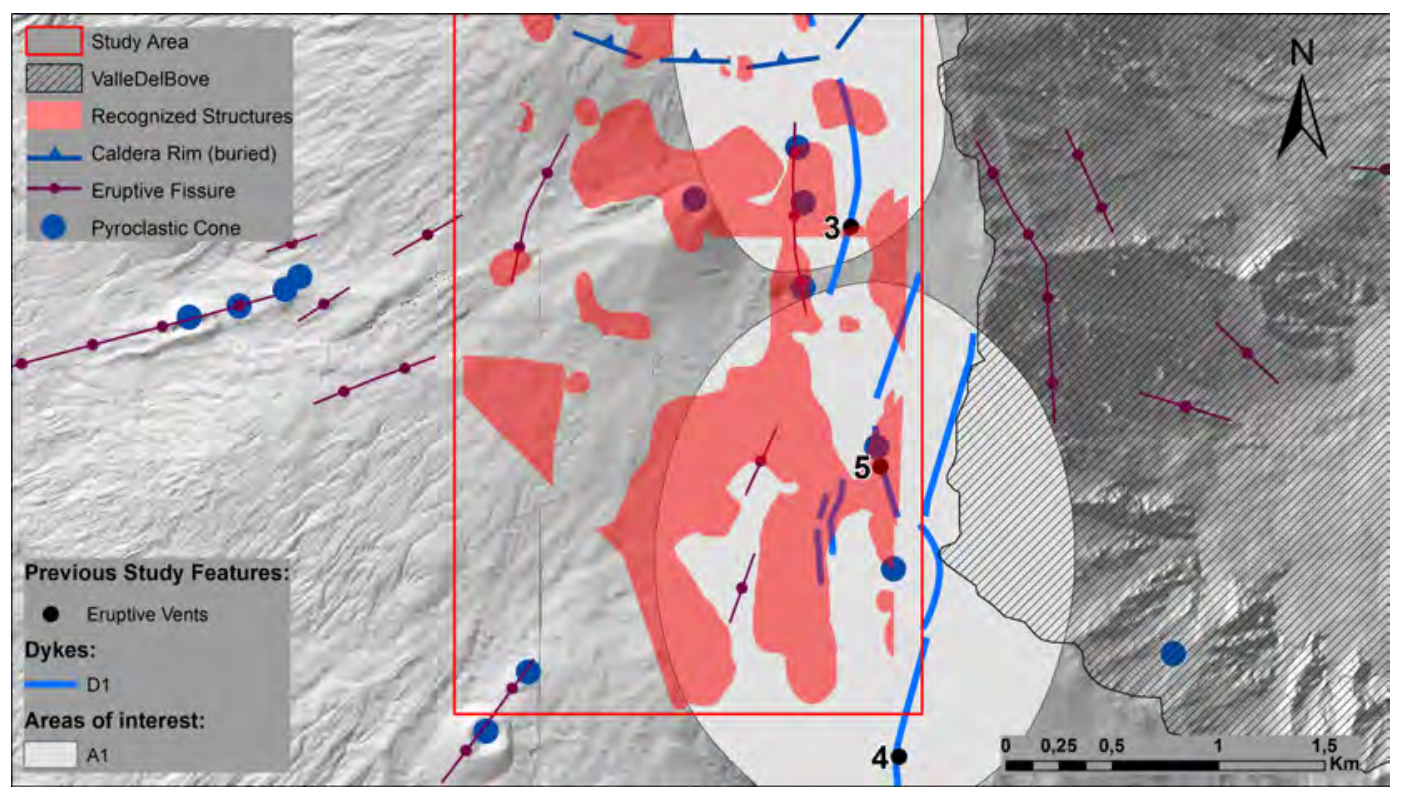

Figure 13: Comparison between the recognized structures in the central and southern clusters and previous studies. The eruptive vents were described by Acocella and Neri [2003]; Behncke and Neri [2003] while the dike D1 and the deformation area A1 were described by Acocella and Neri [2003].

\section{Conclusion}

A joint seismic and GIS experiment targeting the resonant structures located between 1600 and $3200 \mathrm{~m}$ a.s.l. at Mt. Etna volcano is carried out using a dense seismic network with a node spacing of $250 \mathrm{~m}$ and using the Horizontal-to-Vertical-Spectral-Ratio method. The GIS environment provides spatial interpolation between ratiograms, allows a more reliable interpretation of the results by the creation of $2 \mathrm{D}$ and $3 \mathrm{D}$ models of structures with high $\mathrm{H} / \mathrm{V}$ ratios, and precisely connects the results in space with remote sensing studies and geological knowledge. This new methodology increases the level of detail on subsurface shallow structures with a simple and fast analysis. The results confirm previous structural models of the volcano and present important correlations with its recent eruptive and magma dynamics.

Both the methodology and the technology applied have proved to be suitable to (1) the reconstruction of cooled volumes interested by magmatic intrusions in the shallowest portion of the volcano and (2) the understanding of the volcano past and recent dynam- 


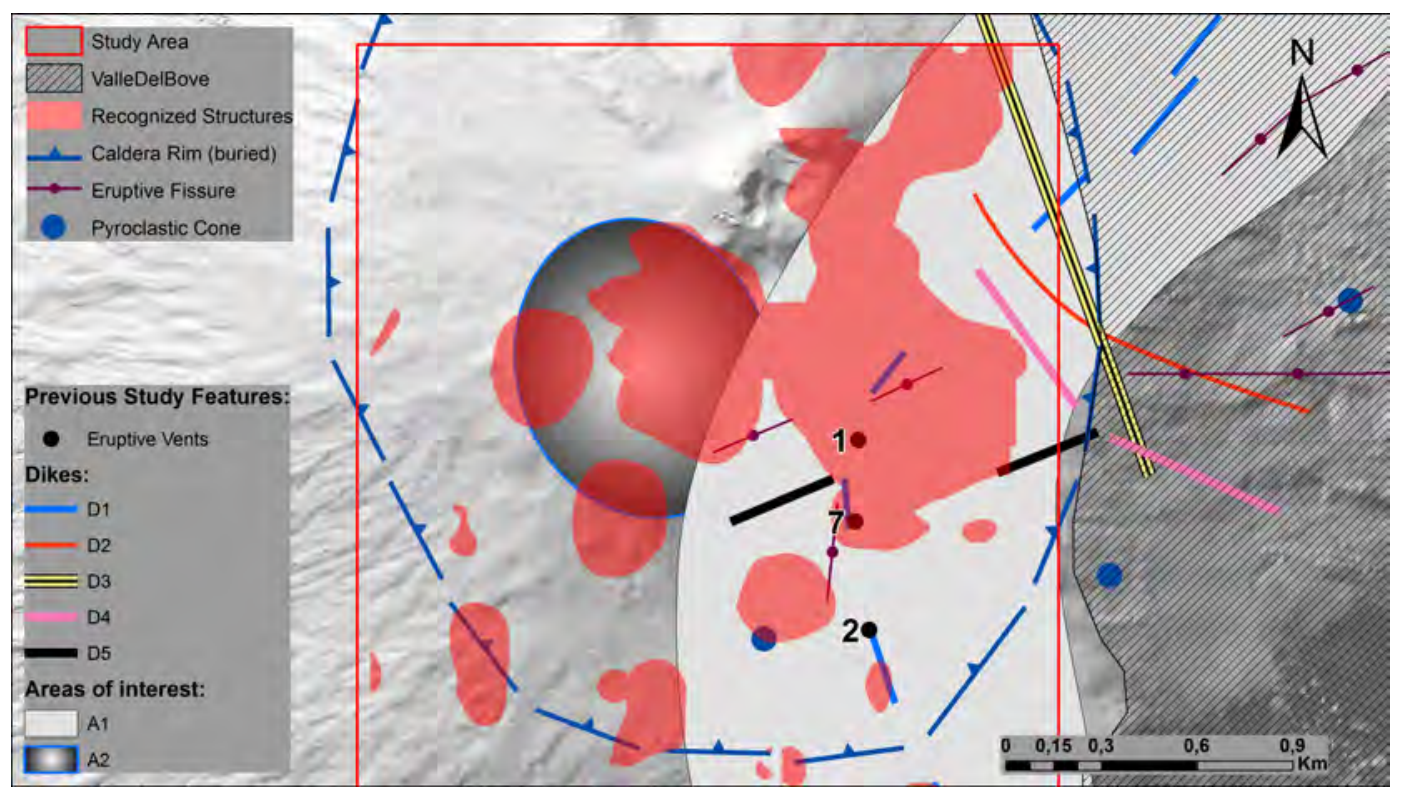

Figure 14: Comparison between the recognized structures in the northern cluster and previous studies.The eruptive vents were described by Acocella and Neri [2003]; Behncke and Neri [2003]. Regarding the dike: D1: [Acocella and Neri, 2003], D2 and D3: [Aloisi et al., 2009], D4: [Bonforte et al., 2013], D5: [Bonforte and Guglielmino, 2015]. The A1 indicates the deformation area highlighted from [Acocella and Neri, 2003] while the A2 is the area where hypocenters are located by Saccorotti et al. [2007].

ics. Repeating the survey in a different time period is a necessary step to (1) confirm the validity of the method; (2) test the method as a dynamic marker of the behaviour of the feeding systems before and after an eruption; (3) develop the platform into a quasi-real time analysis visualization tool for resonating, intrusive, erupting structures. Recent technological advancements in sensor miniaturization are crucial to implement the platform, reducing risks for operators as well as instrumentation costs.

\section{Acknowledgements}

We are very grateful to Professor G. Patanè for the inspiration and financial support; S. La Delfa for assistance during the analysis. We also thank the Parco dell'Etna Staff who ensure the permission and regular support above the volcano. We would like to thank G. Vaccino and F. Zuccarello for the support during the field trip. Two anonymous reviewers provided comments that improved both the interpretation of the results and the clarity 


\section{References}

Valerio Acocella and Marco Neri. What makes flank eruptions? The 2001 Etna eruption and its possible triggering mechanisms. Bulletin of Volcanology, 65(7):517-529, 2003.

Javier Almendros, Francisco Luzón, and Antonio Posadas. Microtremor analyses at Teide Volcano (Canary Islands, Spain): assessment of natural frequencies of vibration using time-dependent horizontal-to-vertical spectral ratios. Geodetic and Geophysical Effects Associated with Seismic and Volcanic Hazards, pages 1579-1596, 2004.

M Aloisi, A Bonaccorso, S Gambino, M Mattia, and G Puglisi. Etna 2002 eruption imaged from continuous tilt and GPS data. Geophysical research letters, 30(23), 2003.

M Aloisi, A Bonaccorso, F Cannavò, S Gambino, M Mattia, G Puglisi, and E Boschi. A new dyke intrusion style for the Mount Etna May 2008 eruption modelled through continuous tilt and GPS data. Terra Nova, 21(4):316-321, 2009.

Salvatore Alparone, Graziella Barberi, Ornella Cocina, Elisabetta Giampiccolo, Carla Musumeci, and Domenico Patanè. Intrusive mechanism of the 2008-2009 Mt. Etna eruption: Constraints by tomographic images and stress tensor analysis. Journal of volcanology and geothermal research, 229:50-63, 2012 .

A Amorosi, S Castellaro, and F Mulargia. Single-Station Passive Seismic Stratigraphy: an inexpensive tool for quick subsurface investigations. GeoActa, 7(10), 2008.

Raffaele Azzaro, Stefano Branca, Klaus Gwinner, and Mauro Coltelli. The volcano-tectonic map of Etna volcano, 1: 100.000 scale: an integrated approach based on a morphotectonic analysis from high-resolution DEM constrained by geologic, active faulting and seismotectonic data. Italian journal of geosciences, 131 (1):153-170, 2012.

Giovanni Barreca, Alessandro Bonforte, and Marco Neri. A pilot GIS database of active faults of Mt. Etna (Sicily): A tool for integrated hazard evaluation. Journal of volcanology and geothermal research, 251: 170-186, 2013.

Boris Behncke and Marco Neri. The July-August 2001 eruption of Mt. Etna (Sicily). Bulletin of Volcanology, 65(7):461-476, 2003.

Marina Bisson, Claudia Spinetti, Marco Neri, and Alessandro Bonforte. Mt. Etna volcano high-resolution topography: airborne LiDAR modelling validated by GPS data. International Journal of Digital Earth, $9(7): 710-732,2016$ 
Alessandro Bonaccorso, Alessandro Bonforte, Sonia Calvari, Ciro Del Negro, Giuseppe Di Grazia, Gaetana Ganci, Marco Neri, Anna Vicari, and Enzo Boschi. The initial phases of the 2008-2009 Mount Etna eruption: A multidisciplinary approach for hazard assessment. Journal of Geophysical Research: Solid Earth, 116(B3), 2011.

Alessandro Bonforte and Francesco Guglielmino. Very shallow dyke intrusion and potential slope failure imaged by ground deformation: The 28 December 2014 eruption on Mount Etna. Geophysical Research Letters, 42(8):2727-2733, 2015.

Alessandro Bonforte, Daniele Carbone, Filippo Greco, and Mimmo Palano. Intrusive mechanism of the 2002 NE-rift eruption at Mt Etna (Italy) modelled using GPS and gravity data. Geophysical Journal International, 169(1):339-347, 2007.

Alessandro Bonforte, Francesco Guglielmino, and Giuseppe Puglisi. Interaction between magma intrusion and flank dynamics at Mt. Etna in 2008, imaged by integrated dense GPS and DInSAR data. Geochemistry, Geophysics, Geosystems, 14(8):2818-2835, 2013.

Stefano Branca, Mauro Coltelli, and Gianluca Groppelli. Geological evolution of Etna volcano. Mt. Etna: volcano laboratory, pages 49-63, 2004.

Stefano Branca, Mauro Coltelli, and Gianluca Groppelli. Geological evolution of a complex basaltic stratovolcano: Mount Etna, Italy. Italian Journal of Geosciences, 130(3):306-317, 2011a.

Stefano Branca, Mauro Coltelli, Gianluca Groppelli, and Fabio Lentini. Geological map of Etna volcano, 1: 50,000 scale. Italian Journal of Geosciences, 130(3):265-291, 2011b.

Daniele Carbone, Dominique Gibert, Jacques Marteau, Michel Diament, Luciano Zuccarello, and Emmanuelle Galichet. An experiment of muon radiography at Mt Etna (Italy). Geophysical Journal International, 196(2):633-643, 2014.

C Cardaci, M Coviello, G Lombardo, G Patanè, and R Scarpa. Seismic tomography of Etna volcano. Journal of volcanology and geothermal research, 56(4):357-368, 1993.

R Cassinis, I Finetti, P Giese, C Morelli, L Steinmetz, and O Vecchia. Deep seismic refraction research on Sicily. Boll. Geof. Teor. Appl, 11(43/44):140-160, 1969.

Francisco J Chávez-García and Tae-Seob Kang. Lateral heterogeneities and microtremors: limitations of HVSR and SPAC based studies for site response. Engineering Geology, 174:1-10, 2014.

Fabien Coutel and Peter Mora. Simulation-based comparison of four site-response estimation techniques. Bulletin of the Seismological Society of America, 88(1):30-42, 1998.

Gilda Currenti, Rosalba Napoli, and Ciro Del Negro. Toward a realistic deformation model of the 2008 magmatic intrusion at Etna from combined DInSAR and GPS observations. Earth and Planetary Science Letters, 312(1):22-27, 2011.

Emanuela De Beni, Stefano Branca, Mauro Coltelli, Gianluca Groppelli, and Jan R Wijbrans. 40Ar/39Ar 
isotopic dating of Etna volcanic succession. Italian Journal of Geosciences, 130(3):292-305, 2011.

P. De Gori, C. Chiarabba, and D. Patanè. Qp structure of Mount Etna: Constraints for the physics of the plumbing system. Journal of Geophysical Research, 110(B05303):doi:10.1029/2003JB002875, 1999.

G De Luca, L Filippi, G Patanè, R Scarpa, and S Vinciguerra. Three-dimensional velocity structure and seismicity of Mt. Etna volcano, Italy. Journal of volcanology and geothermal research, 79(1):123-138, 1997.

L. De Siena, E. Del Pezzo, and F. Bianco. Campi Flegrei seismic attenuation image: evidences of gas resevoirs, hydrotermal basins and feeding systems. Journal of Geophysical Research, 115(B0):9312-9329, 2010.

L De Siena, C Thomas, and R Aster. Multi-scale reasonable attenuation tomography analysis (MuRAT): An imaging algorithm designed for volcanic regions. Journal of Volcanology and Geothermal Research, 277:22-35, 2014.

Luca De Siena, Marie Calvet, Keira J Watson, ART Jonkers, and Christine Thomas. Seismic scattering and absorption mapping of debris flows, feeding paths, and tectonic units at Mount St. Helens volcano. Earth and Planetary Science Letters, 442:21-31, 2016.

Ciro Del Negro, Annalisa Cappello, Marco Neri, Giuseppe Bilotta, Alexis Hérault, and Gaetana Ganci. Lava flow hazards at Mount Etna: constraints imposed by eruptive history and numerical simulations. Scientific reports, 3, 2013.

M Dravinski, G Ding, and K-L Wen. Analysis of spectral ratios for estimating ground motion in deep basins. Bulletin of the Seismological Society of America, 86(3):646-654, 1996.

Edward H Field and Klaus H Jacob. A comparison and test of various site-response estimation techniques, including three that are not reference-site dependent. Bulletin of the seismological society of America, 85 (4):1127-1143, 1995.

Pinde Fu and Jiulin Sun. Web GIS: principles and applications. Esri Press, 2010.

Antonio Galgaro, Jacopo Boaga, and Michele Rocca. HVSR technique as tool for thermal-basin characterization: a field example in NE Italy. Environmental Earth Sciences, 71(10):4433-4446, 2014.

PY Gillot, G Kieffer, and R Romano. The evolution of Mount Etna in the light of potassium-argon dating. Acta Vulcanol, 5:81-87, 1994.

Zohar Gvirtzman and Amos Nur. The formation of Mount Etna as the consequence of slab rollback. Nature, 401(6755):782-785, 1999.

Alfred Hirn, Alexandre Nercessian, Martine Sapin, Fabrizio Ferrucci, and Gérard Wittlinger. Seismic heterogeneity of Mt Etna: structure and activity. Geophysical Journal International, 105(1):139-153, 1991.

Malte Ibs-von Seht and Jürgen Wohlenberg. Microtremor measurements used to map thickness of soft sediments. Bulletin of the Seismological Society of America, 89(1):250-259, 1999. 
Eric Kiser, Imma Palomeras, Alan Levander, Colin Zelt, Steven Harder, Brandon Schmandt, Steven Hansen, Kenneth Creager, and Carl Ulberg. Magma reservoirs from the upper crust to the Moho inferred from high-resolution Vp and Vs models beneath Mount St. Helens, Washington State, USA. Geology, 44(6): 411-414, 2016.

Katsuaki Konno and Tatsuo Ohmachi. Ground-motion characteristics estimated from spectral ratio between horizontal and vertical components of microtremor. Bulletin of the Seismological Society of America, 88 (1):228-241, 1998.

I. Koulakov, D. Bindi, S. Parolai, H. Grosser, and C. Milkereit. Distribution of Seismic Velocities and Attenuation in the Crust Beneath the North Anatolian Fault (Turkey) from Local Earthquake Tomography. Bulletin of the Seismological Society of America, 100(1):207-224, 2010.

Ivan Koulakov. Studying deep sources of volcanism using multiscale seismic tomography. Journal of Volcanology and Geothermal Research, 2013.

Corinne Lachet, Denis Hatzfeld, Pierre-Yves Bard, Nikos Theodulidis, Christos Papaioannou, and Alekos Savvaidis. Site effects and microzonation in the city of Thessaloniki (Greece) comparison of different approaches. Bulletin of the Seismological Society of America, 86(6):1692-1703, 1996.

Corinne Lachetl and Pierre-Yves Bard. Numerical and Theoretical Investigations on the Possibilities and Limitations of Nakamura's Technique. Journal of Physics of the Earth, 42(5):377-397, 1994.

G Lanzafame and JC Bousquet. The Maltese escarpment and its extension from Mt. Etna to Aeolian Islands (Sicily): importance and evolution of a lithosphere discontinuity. Acta Vulcanologica, 9:113-120, 1997.

J. M. Lees and G. T. Lindley. Three-dimensional Attenuation Tomography at Loma Prieta: Inverting t* for Q. Journal of Geophysical Research, 99(B4):6843-6863, 1994.

F Lentini. The geology of the Mt. Etna basement, Mem. Soc. Geol. Ital, 23:7-25, 1982.

Javier Lermo and Francisco J Chávez-García. Are microtremors useful in site response evaluation? Bulletin of the seismological society of America, 84(5):1350-1364, 1994.

RP Middlemiss, A Samarelli, DJ Paul, J Hough, S Rowan, and GD Hammond. Measurement of the Earth tides with a MEMS gravimeter. Nature, 531(7596):614-617, 2016.

Mauricio M Mora, Philippe Lesage, Jacques Dorel, Pierre-Yves Bard, Jean-Philippe Métaxian, Guillermo E Alvarado, and Carlos Leandro. Study of seismic site effects using H/V spectral ratios at Arenal Volcano, Costa Rica. Geophysical research letters, 28(15):2991-2994, 2001.

Yutaka Nakamura. A method for dynamic characteristics estimation of subsurface using microtremor on the ground surface. Railway Technical Research Institute, Quarterly Reports, 30(1), 1989.

Marco Neri, Valerio Acocella, Boris Behncke, Salvatore Giammanco, Francesco Mazzarini, and Derek Rust. Structural analysis of the eruptive fissures at Mount Etna (Italy). Annals of Geophysics, 54(5), 2011.

J. Neuberg and T. Pointer. Effects of volcano topography on seismic broad-band waveforms. Geophysical 
Journal International, 143:239-248, 2000. doi: 10.1046/j.1365-246x.2000.00251.xs.

M Nogoshi and T Igarashi. On the propagation characteristics of microtremors. J. Seism. Soc. Japan, 23: 264-280, 1970.

M Nogoshi and T Igarashi. On the amplitude characteristics of microtremor (part 2). Jour. Seism. Soc. Japan, 24:26-40, 1971.

S Parolai, P Bormann, and C Milkereit. New relationships between Vs, thickness of sediments, and resonance frequency calculated by the $\mathrm{H} / \mathrm{V}$ ratio of seismic noise for the Cologne area (Germany). Bulletin of the Seismological Society of America, 92(6):2521-2527, 2002.

D. Patanè, G. Barberi, O. Cocina, P. De Gori, and C. Chiarabba. Time-Resolved Seismic Tomography Detects Magma Intrusions at Mount Etna. Science, 313:821-823, 2006a.

Domenico Patanè, Claudio Chiarabba, Omella Cocina, Pasquale De Gori, Milena Moretti, and Enzo Boschi. Solid Earth-135. Tomographic images and 3D earthquake locations of the seismic swarm preceding the 2001 Mt. Etna eruption: Evidence for a dyke intrusion (DOI 10.1029/2001GLO14391). Geophysical Research Letters, 29(10), 2002.

Domenico Patanè, Pasquale De Gori, Claudio Chiarabba, and Alessandro Bonaccorso. Magma ascent and the pressurization of Mount Etna's volcanic system. Science, 299(5615):2061-2063, 2003.

Giuseppe Patanè, Santo La Delfa, and Jean-Claude Tanguy. Volcanism and mantle-crust evolution: the Etna case. Earth and Planetary Science Letters, 241(3):831-843, 2006b.

Gilberto Saccorotti, Ivan Lokmer, Christopher J Bean, Giuseppe Di Grazia, and Domenico Patanè. Analysis of sustained long-period activity at Etna Volcano, Italy. Journal of volcanology and geothermal research, 160(3):340-354, 2007.

Linda C Seekins, Leif Wennerberg, Lucia Margheriti, and Hsi-Ping Liu. Site amplification at five locations in San Francisco, California: A comparison of S waves, codas, and microtremors. Bulletin of the Seismological Society of America, 86(3):627-635, 1996.

ADL Sharp, PM Davis, and F Gray. A low velocity zone beneath Mount Etna and magma storage. Nature, $287: 587-591,1980$

U. Wegler. Analysis of Multiple Scattering at Vesuvius Volcano, Italy, using Data of the TomoVes active seismic experiment. Journal of Volcanology and Geothermal Research, 128:45-63, 2003. 